\title{
The real-time city? Big data and smart urbanism
}

\author{
Rob Kitchin
}

Published online: 29 November 2013

(C) Springer Science+Business Media Dordrecht 2013

\begin{abstract}
Smart cities' is a term that has gained traction in academia, business and government to describe cities that, on the one hand, are increasingly composed of and monitored by pervasive and ubiquitous computing and, on the other, whose economy and governance is being driven by innovation, creativity and entrepreneurship, enacted by smart people. This paper focuses on the former and, drawing on a number of examples, details how cities are being instrumented with digital devices and infrastructure that produce 'big data'. Such data, smart city advocates argue enables real-time analysis of city life, new modes of urban governance, and provides the raw material for envisioning and enacting more efficient, sustainable, competitive, productive, open and transparent cities. The final section of the paper provides a critical reflection on the implications of big data and smart urbanism, examining five emerging concerns: the politics of big urban data, technocratic governance and city development, corporatisation of city governance and technological lock-ins, buggy, brittle and hackable cities, and the panoptic city.
\end{abstract}

Keywords Big data $\cdot$ Smart cities $\cdot$ Urbanism . Real-time analysis · Data analytics · Ubiquitous computing - Governance

R. Kitchin $(\square)$

NIRSA, National University of Ireland Maynooth, County

Kildare, Ireland

e-mail: Rob.Kitchin@nuim.ie

\section{Introduction}

For the past two decades, urban analysts and theorists have been charting the evolution of cities during an era where information and communication technologies (ICTs) have been exerting a growing and pervasive influence on the nature, structure and enactment of urban infrastructure, management, economic activity and everyday life. Cities which have embraced ICT as a development strategy, being pioneers in embedding digital infrastructure and systems into their urban fabric and utilising them for entrepreneurial and regulatory effect, have been variously labelled as 'wired cities' (Dutton et al. 1987), 'cyber cities' (Graham and Marvin 1999), 'digital cities' (Ishida and Isbister 2000), 'intelligent cities' (Komninos 2002), 'smart cities' (Hollands 2008) or 'sentient cities' (Shepard 2011). Whilst each of these terms is used in a particular way to conceptualise the relationship between ICT and contemporary urbanism, they share a focus on the effects of ICT on urban form, processes and modes of living, and in recent years have been largely subsumed within the label 'smart cities', a term which has gained traction in business and government, as well as academia.

The term 'smart city' has been variously defined within the literature, but can broadly be divided into two distinct but related understandings as to what makes a city 'smart'. On the one hand, the notion of a 'smart city' refers to the increasing extent to which urban places are composed of 'everyware' (Greenfield 
2006); that is, pervasive and ubiquitous computing and digitally instrumented devices built into the very fabric of urban environments (e.g., fixed and wireless telecom networks, digitally controlled utility services and transport infrastructure, sensor and camera networks, building management systems, and so on) that are used to monitor, manage and regulate city flows and processes, often in real-time, and mobile computing (e.g., smart phones) used by many urban citizens to engage with and navigate the city which themselves produce data about their users (such as location and activity). Connecting up, integrating and analysing the information produced by these various forms of everyware, it is argued, provides a more cohesive and smart understanding of the city that enhances efficiency and sustainability (Hancke et al. 2013, Townsend 2013) and provides rich seams of data that can used to better depict, model and predict urban processes and simulate the likely outcomes of future urban development (Schaffers et al. 2011; Batty et al. 2012). Everyware thus works to make a city knowable and controllable in new, more fine-grained, dynamic and interconnected ways that "improve[s] the performance and delivery of public services while supporting access and participation" (Allwinkle and Cruickshank 2011: 2). It also provides the supporting infrastructure for business activity and growth and stimulates new forms of entrepreneurship, especially with respect to the service and knowledge economy.

On the other hand, the notion of a 'smart city' is seen to refer more broadly to the development of a knowledge economy within a city-region (Kourtit et al. 2012). From this perspective, a smart city is one whose economy and governance is being driven by innovation, creativity and entrepreneurship, enacted by smart people. Here, ICT is seen as being of central importance as the platform for mobilising and realising ideas and innovations, especially with respect to professional services. In and of itself, however, the embedding of ICT in urban infrastructure is not seen to make a city smart (Hollands 2008). In other words, it is how ICT, in conjunction with human and social capital and wider economic policy, is used to leverage growth and manage urban development that makes a city smart (Caragliu et al. 2009). Whereas the first vision of a smart city focuses on ICT and its use in managing and regulating the city from a largely technocratic and technological perspective, the second encompasses policies related to human capital, education, economic development and governance and how they can be enhanced by ICT. In this scenario, networked infrastructures are enabling technologies, the undergirding platform for innovation and creativity, that facilitates social, environmental, economic, and cultural development (Allwinkle and Cruickshank 2011).

What unites these two visions of a smart city is an underlying neoliberal ethos that prioritises market-led and technological solutions to city governance and development, and it is perhaps no surprise that some of the strongest advocates for smart city development are big business (e.g., IBM, CISCO, Microsoft, Intel, Siemens, Oracle, SAP) that, on the one hand, are pushing for the adoption of their new technologies and services by cities and states and, on the other, are seeking deregulation, privatisation and more open economies that enable more efficient capital accumulation. For city officials, national governments and supra-national states such as the European Union, smart cities offer the enticing potential of socioeconomic progress-more liveable, secure, functional, competitive and sustainable cities, and the renewal of urban centres as hubs of innovation and work (Kourtit et al. 2012; Townsend 2013). Hollands (2008) thus identifies five main characteristics of a smart city as evidenced by industry and government literature: widespread embedding of ICT into the urban fabric; business-led urban development and a neoliberal approach to governance; a focus on social and human dimensions of the city from a creative city perspective (alia Florida 2004); the adoption of a smarter communities agenda with programmes aimed at social learning, education and social capital; and a focus on social and environmental sustainability. These five characteristics, Hollands (2008) suggests, leads to an inevitable tension within smart cities between: serving global, mobile capital and stationary ordinary citizens; attracting and retaining an elite creative class and serving other classes; and top-down, corporatized, centralized development and bottom-up, grassroots, decentralised and diffuse approaches.

Another vital conjoin between these two visions of a smart city is the prioritisation of data capture and analysis as a means for underpinning evidenceinformed policy development, enacting new modes of technocratic governance, empowering citizens through open, transparent information, and stimulating economic innovation and growth. Data are thus viewed as essential constituent material to realising a 
smart city vision. Such data are seen as providing objective, neutral measures that are free of political ideology as to what is occurring in a city, with the weight of data speaking an inherent truth about social and economic relations and thus providing robust empirical evidence for policy and practice (MayerSchonberger and Cukier 2013). And yet, there has been to date been little critical focus on the new forms of data being produced (or not produced), how they are being mobilised by business, government and citizens, and the implications of real-time data analytics.

In this paper, the data explosion that has occurred over the past decade, the role of cities as key sites in the production of such data, and how these data are being used to re-imagine and regulate the urban life are examined. In particular, the analysis concentrates on the new phenomena of 'big data' and the generation of enormous, varied, dynamic, and interconnected datasets that hold the promise of what some see as a truly smart city-one that can be known and managed in real-time and is sentient to some degree (Batty et al. 2012; Townsend 2013). I detail a number of projects that aim to produce a real-time overview and analysis of the city, and provide a critical reflection on big data and smart urbanism.

\section{Big data and cities}

There has long been the production of very large datasets, such as national censuses, government records and geomatic surveys, that provide information about cities and their citizens. Likewise, businesses have collated significant amounts of data about their operations, markets and customers. However, these datasets often rely on samples, are generated on a non-continuous basis, the number of variables are quite small, are aggregated to a relatively coarse spatial scale, and are often limited in access. As a result, these large datasets have been complemented by what might be termed 'small data' studiesquestionnaire surveys, case studies, city audits, interviews and focus groups, and ethnographies-that capture a relatively limited sample of data that are tightly focused, time and space specific, restricted in scope and scale, and relatively expensive to generate and analyze, to provide additional depth and insight with respect to specific phenomena. Much of what we know about cities to date then has been gleaned from studies that are characterised by data scarcity (Miller 2010).

The hype and hope of big data is a transformation in the knowledge and governance of cities through the creation of a data deluge that seeks to provide much more sophisticated, wider-scale, finer-grained, realtime understanding and control of urbanity. There is no agreed academic or industry definition of big data, but a survey of the emerging literature denotes a number of key features. Big data are:

- huge in volume, consisting of terabytes or petabytes of data;

- high in velocity, being created in or near real-time;

- diverse in variety, being structured and unstructured in nature, and often temporally and spatially referenced;

- exhaustive in scope, striving to capture entire populations or systems $(\mathrm{n}=$ all $)$, or at least much larger sample sizes than would be employed in traditional, small data studies;

- fine-grained in resolution, aiming to be as detailed as possible, and uniquely indexical in identification;

- relational in nature, containing common fields that enable the conjoining of different data sets;

- flexible, holding the traits of extensionality (can add new fields easily) and scaleability (can expand in size rapidly).

(see Boyd and Crawford 2012; Dodge and Kitchin 2005; Laney 2001; Marz and Warren 2012; MayerSchonberger and Cukier 2013; Zikopoulos et al. 2012).

In other words, big data consists of massive, dynamic, varied, detailed, inter-related, low cost datasets that can be connected and utilised in diverse ways, thus offering the possibility of studies shifting from: data-scarce to data-rich; static snapshots to dynamic unfoldings; coarse aggregation to high resolution; relatively simple hypotheses and models to more complex, sophisticated simulations and theories (Kitchin 2013).

There is little doubt that since the early 2000 s there has been a transformation in the volume of data generated. Zikopoulos et al. (2012) detail that in 2000 c. 800,000 petabytes $\left(2^{50}\right.$ bytes $)$ of data were stored in the world. By 2010, MGI (cited in Manyika et al. 2011: 3) "estimated that enterprises globally stored more than 7 exabytes $\left[2^{60}\right.$ bytes] of new data on disk 
drives... while consumers stored more than six exabytes of new data on devices such as PCs and notebooks." They further estimated that in "2009, nearly all sectors in the US economy had at least an average of 200 terabytes $\left[2^{40}\right.$ bytes] of stored data... per company with more than 1,000 employees. Many sectors had more than one petabyte in mean stored data per company." Based on their review of data volume growth, Manyika et al. (2011) projected a growth of $40 \%$ in data generated globally per year. Such is the phenomenal growth in data production, Hal Varian, Chief Economist at Google (cited in Smolan and Erwitt 2012), estimates that more data are being produced every 2 days at present than in all of history prior to 2003 and Zikopoulos et al. (2012) expects data volumes to reach 35 zetabytes [ $2^{70}$ bytes] by 2020 . In 2013, EU commissioner for Digital Agenda, Neelie Kroes, stated that 1.7 million billion bytes of data per minute were being generated globally (Rial 2013).

Such explosive growth in data is due to a number of different enabling and driving technologies, infrastructures, techniques and processes, and their rapid embedding into everyday practices and spaces. These include the widespread roll-out of fixed and mobile internet; the development of ubiquitous computing and the ability to access networks and computation in many environments and on the move; the embedding of software into all kinds of machines transforming them from 'dumb' to 'smart' and the creation of a plethora of purely digital devices; the roll-out of social media and Web 2.0 applications; advances in database design and systems of information management; the distributed storage of data at affordable costs; and new forms of data analytics designed to cope with data abundance (Dodge and Kitchin 2005; Greenfield 2006; Kitchin and Dodge 2011). These developments not only enable the accessing and sharing of data, but are also the means by which much big data are generated. For example, mobile devices such as smartphones allow their users to access information at the same time as they record the information accessed, and when and where it was requested and how it was used.

The sources of big data can be broadly divided into three categories: directed, automated and volunteered. Directed data are generated by traditional forms of surveillance, wherein the gaze of the technology is focused on a person or place by a human operator. Such systems include immigration passport control where passenger details are collected and checked against various databases in real-time, and new data are generated such as CCTV, photographs, fingerprints or iris scans; or spatial video, LiDAR, thermal or other kinds of electromagnetic scans of environments that enables mobile and real-time 2D and 3D mapping. In the case of automated data, data are generated as an inherent, automatic function of the device or system. There are a number of different means by which automated data are produced, including: capture systems, in which the means of performing a task captures data about that task (such as scanning items at a check-out till being used to monitor the till-operators performance, as well as collecting information with regards to the items purchased and who purchased them); digital devices, such as mobile phones, that record and communicate the history of their own use; transactions and interactions across digital networks that not only transfer information, but generate data about the transactions and interactions themselves (such as indexical logs of payments or bank transfers or email); clickstream data that records how people navigate through a website or app; sensed data generated by a variety of sensors and actuators embedded into objects or environments that regularly communicate their measurements; the scanning of machine-readable objects such as travel passes, passports, or barcodes on parcels that register payment and movement through a system; and machine to machine interactions across the internet of things (Kitchin and Dodge 2011). In contrast, volunteered data are gifted by users. These include: interactions across social media such as the posting of comments, observations and the uploading of photos to social networking sites such as Facebook or Twitter; and the crowdsourcing of data wherein users generate data and then contribute them to a common system, such as the generation of GPS-traces uploaded into OpenStreetMap to create a common, open mapping system (Kitchin and Dodge 2011; Sui et al. 2012).

Whilst directed and volunteered data can provide useful insights into urban systems and city lives, it is automated forms of data generation that have most caught the imagination of those concerned with understanding and managing cities. In particular, there has been an interest in automated forms of surveillance, sensor networks and the internet of things, and the tracking and tracing of people and objects. Here, the city is envisaged as "constellations of instruments across many scales that are connected through 
multiple networks which provide continuous data regarding the movements of people and materials" and the status of various structures and systems (Batty et al. 2012: 482). As such, the instrumented city offers the promise of an objectively measured, real-time analysis of urban life and infrastructure.

Automated forms of surveillance include: anonymous paper tickets being replaced with automatically trackable 'smart cards'; automatic number plate recognition (ANPR) systems that use digital cameras to scan license plates and pattern match the details to owner details and can be used to trace vehicles as they cross a city and provide inputs into intelligent transportation systems (ITS); automatic meter reading (AMR) that communicates utility usage without the need for manual reading and can do so on a continuous basis; and automated monitoring of public service provision, such as RFID chips attached to rubbish bins detecting whether they have been collected (Dodge and Kitchin 2007a; Hancke et al. 2013). Sensor networks consist of an array of very small, inexpensive sensors or actuators that can be embedded or placed on different structures to measure specific outputs such as levels of light, humidity, temperature, gas, electrical resistivity, acoustics, air pressure, movement, speed, and so on. Sensors can be passive and read by scanners, or can be active, broadcasting data at regular intervals over local or wide area networks, or they might have near field communication (NFC) capabilities that enables two-way communication (Hancke et al. 2013). Sensors networks can be used to monitor the use and condition of public infrastructures, such as bridges, roads, buildings, and utility provision, as well as general environmental conditions within a city.

Urban places are also now full of objects and machines that are uniquely indexical that conduct automatic work and are part of the internet of things, communicating about their use and traceable if they are mobile. These include automatic doors, lighting and heating systems, security alarms, wifi router boxes, entertainment gadgets, television recorders, and so on. Many of these devices transfer data between each other, in turn leading to new derived data. Devices such as mobile phones can be traced through space by triangulation across phone masts and others with built-in GPS receivers, such as mobile phones, tablets, and satnavs, can record and transmit their own trails. Transponders can be used to monitor throughput at toll-booths, measuring vehicle flow along a road or the number of empty spaces in a car park, and track the progress of buses and trains along a route, and smart tickets, such as the Oyster card on the London Underground, can be used to trace passenger travel. All of these forms of data are growing rapidly (by 2013 over ten billion objects were connected to the in internet of things, with this set to rise to over 50 billion by 2020; Farber 2013).

Some of these data are generated by local governments and state agencies, and some by private companies, and by no means are they all open in nature. Nevertheless for urban managers these forms of instrumentation provide abundant, systematic, dynamic, well-defined, resolute, relatively cheap data about city activities and processes, enabling the possibility of real-time analytics and adaptive forms of management and governance (Kloeckl et al. 2012).

\section{The real-time city}

Many city governments now use real-time analytics to manage aspects of how a city functions and is regulated. Perhaps the most common example relates to movement of vehicles around a transportation network, where data from a network of cameras and transponders are fed back to a central control hub to monitor the flow of traffic and to adjust traffic light sequences and speed limits and to automatically administer penalties for traffic violations (Dodge and Kitchin 2007a). Similarly, the police might monitor a suite of cameras and live incident logs in order to efficiently and reactively direct appropriate resources to particular locations. Data relating to environmental conditions might be collated from a sensor network distributed throughout the city, for example measuring air pollution, water levels or seismic activity. Many local governments use management systems to $\log$ public engagement with their services and to monitor whether staff have dealt with any issues. In nearly all cases, these are isolated systems dealing with a single issue and are controlled by a single agency.

More recently there has been an attempt to draw all of these kinds of surveillance and analytics into a single hub, supplemented by broader public and open data analytics. For example, the Centro De Operacoes Prefeitura Do Rio ${ }^{1}$ in Rio de Janeiro, Brazil, a

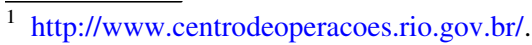




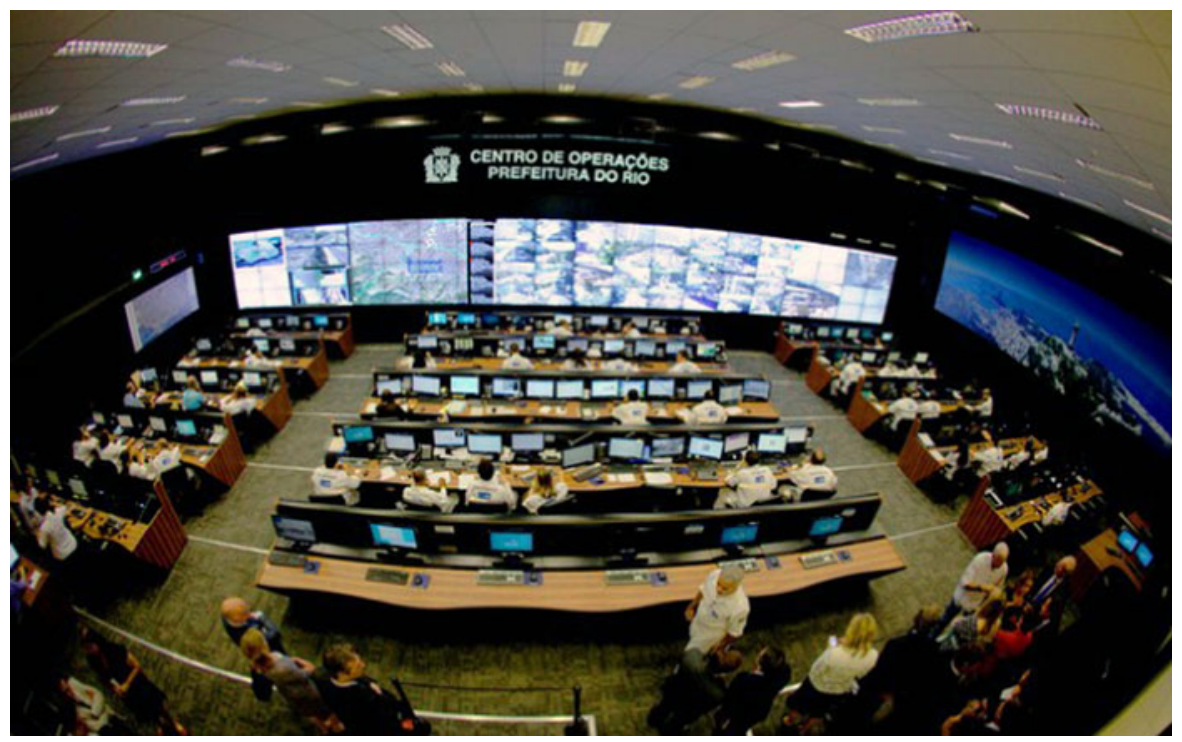

Fig. 1 The Centro De Operacoes Prefeitura Do Rio in Rio de Janeiro, Brazil. Source George Magaraia, http://ultimosegundo.ig.com. br/brasil/rj/2012-05-03/ig-visita-o-centro-de-operacoes-do-rio-de-janeiro.html

partnership between the city government and IBM, have created a citywide instrumented system that draws together data streams from thirty agencies, including traffic and public transport, municipal and utility services, emergency services, weather feeds, and information sent in by employees and the public via phone, internet and radio, into a single data analytics centre (see Fig. 1). Here, algorithms and a team of analysts process, visualize, analyze and monitor a vast amount of live service data, alongside data aggregated over time and huge volumes of administration data that are released on a more periodic basis, often mashing the datasets together to investigate particular aspects of city life and change over time, and to build predictive models with respect to everyday city development and management and disaster situations such as flooding. This is complemented by a virtual operations platform that enables city officials to log-in from the field to access real-time information. For example, police at an accident scene can use the platform to see how many ambulances have been dispatched and when, and to upload additional information (Singer 2012). The stated aim of the city's mayor, Eduardo Paes, was "to knock down silos... [between] departments and combine each one's data to help the whole enterprise" (Singer 2012).

Similarly, the Office of Policy and Strategic Planning for New York city has sought to create a one-stop data analytic hub to weave together data from a diverse set of city agencies in order to try and manage, regulate and plan the city more efficiently and effectively. Terabytes of data stream through the office on a daily basis enabling the analysts to crossreference data, spot patterns and identify and solve city problems (Feuer 2013). They have also started to make some of the data available in open form, ${ }^{2}$ enabling developers to build apps that take the data and rework and repackage it for daily consumption by city dwellers. Likewise, Dublinked, ${ }^{3}$ provides operational data from Dublin's four local authorities in an open format, and many other municipal governments around the world have started to release various kinds of administrative and operational data using various kinds of open data models (see Ferro and Osella 2013 for an overview of eight different models). An example of an app using such open municipal data is SmartSantanderRA an augmented reality app that provides information on about 2,700 places in the city of Santander (beaches, park and gardens, monuments, points of interest (POI), tourism offices, shops, galleries, museums, libraries, public buses, taxis, bikes, parking places, and so on), along with real time access to traffic and beaches cameras, weather reports

\footnotetext{
$\overline{2}$ https://nycopendata.socrata.com/.

${ }^{3}$ http://www.dublinked.ie/.
} 


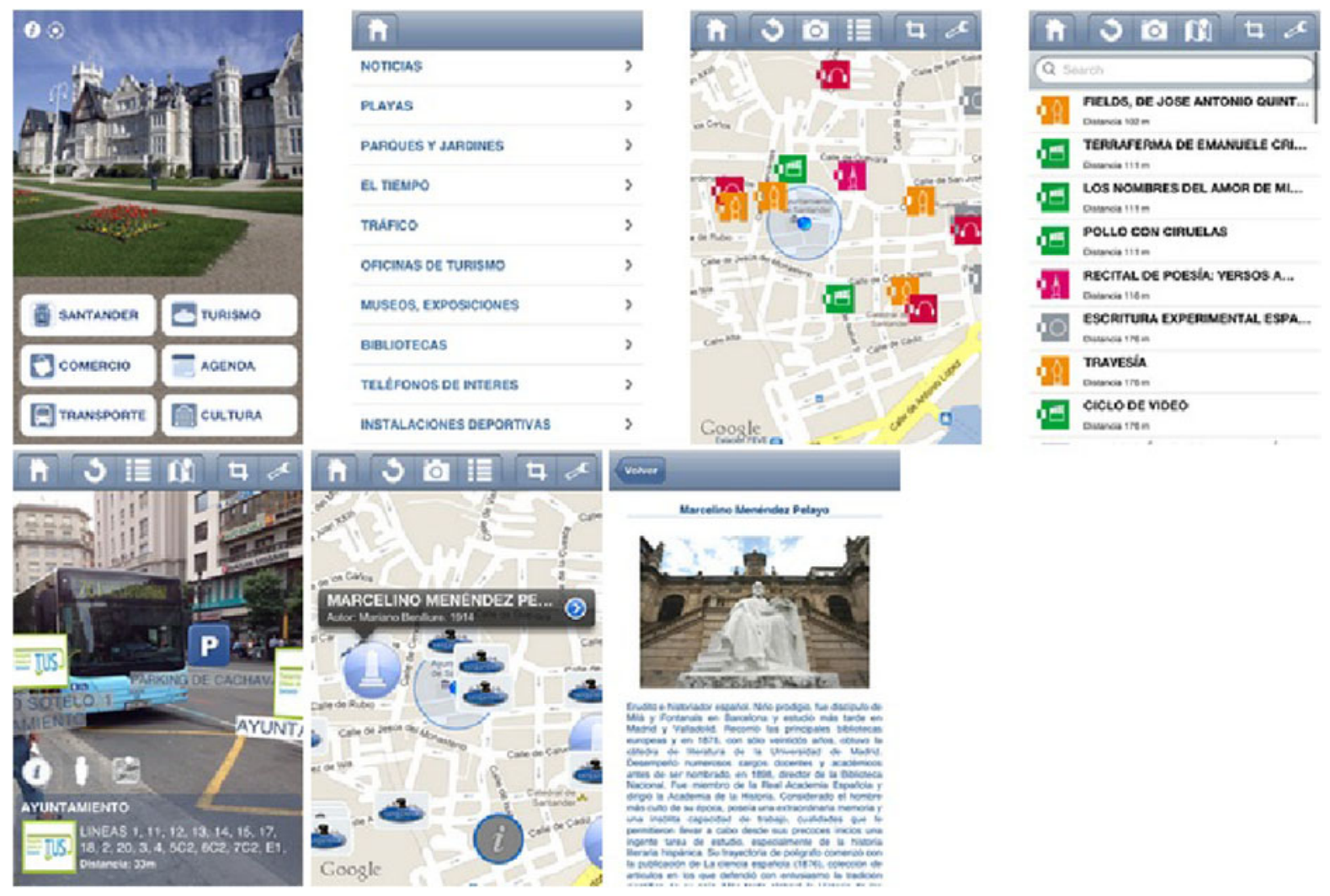

Fig. 2 SmartSantanderRA augmented reality app. Source http://www.smartsantander.eu/index.php/blog/item/174-smartsantanderrasantander-augmented-reality-application?template=retro

and forecast, public buses information and bike-rental service $^{4}$ (see Fig. 2).

In other cities, such as London, live feeds of realtime data are being communicated to citizens through what have been termed 'city dashboards'. For example, in the London case ${ }^{5}$ (Fig. 3), developed by CASA at UCL, citizens can find out real-time information about the weather, air pollution, public transport delays, public bike availability, river level, electricity demand, the stock market, twitter trends in the city, look at traffic camera feeds, and even the happiness level. These data can also be mapped. This is complemented by the London Dashboard, ${ }^{6}$ a data visualisation site that tracks the performance of the city with respect to twelve key areas-jobs and economy, transport, environment, policing and crime,

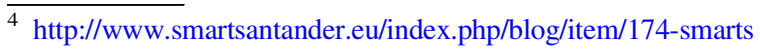
antanderra-santander-augmented-reality-application.

5 http://citydashboard.org/london/.

6 http://data.london.gov.uk/london-dashboard.
}

fire and rescue, communities, housing, health, and tourism - though these data are more administrative in nature and not in real-time. Rather than simply providing the raw data, these sites produce visualisations that aid the interpretation and analysis, especially for non-expert users, and allow citizens to monitor the city for themselves and for their own ends.

For those developing and using integrated, realtime city data analytics, such centres, apps and dashboards provide a powerful means for making sense of, managing and living in the city in the hereand-now, and for envisioning and predicting future scenarios. Rather than basing decisions on anecdote or intuition or clientelist politics or periodic/partial evidence, it is possible to assess what is happening at any one time and to react and plan appropriately. Moreover, the use of large samples and the linking of diverse forms of data provide a deeper, more holistic and robust analysis. For advocates of such systems it thus becomes possible to develop, run, regulate and live in the city on the basis of strong, rationale 


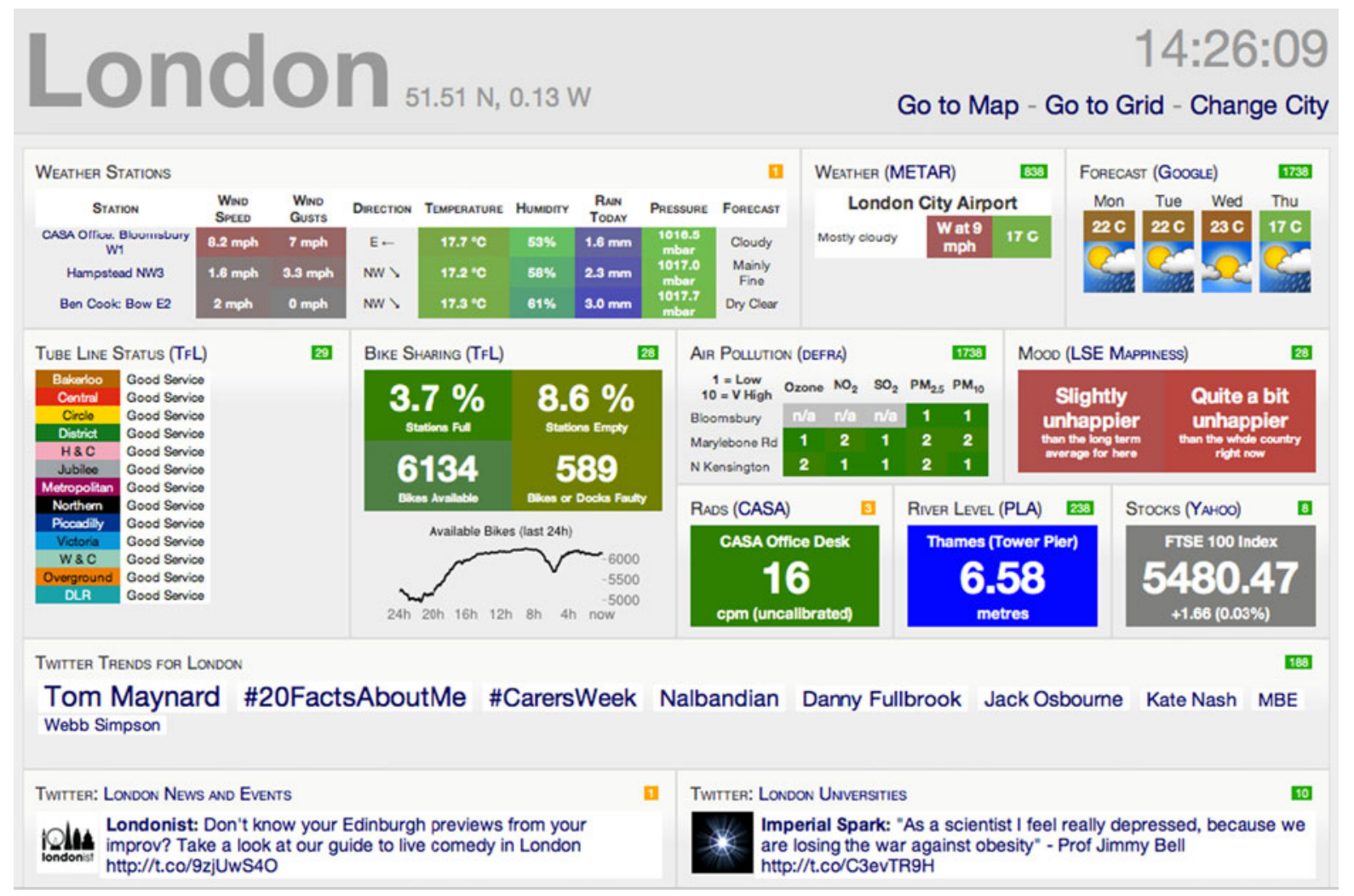

Fig. 3 CASA's London City Dashboard. Source http://citydashboard.org/london/

evidence rather weak, selective evidence and political ideology. As such, it is argued, the use of such big data provides the basis for a more efficient, sustainable, competitive, productive, open and transparent city. But just as smart urbanism underpinned by big data offers a seemingly attractive vision of future cities, it also raises a number of concerns, five of which will now be examined in brief.

\section{Five concerns about a real-time city}

The politics of big urban data

Data within smart city initiatives are portrayed as being benign and lacking in political ideology. Data are simply data: natural and essential elements that are abstracted from the world in neutral and objective ways subject to technical constraints. Sensors and cameras have no politics or agenda. They simply measure light or heat or humidity, and so onproducing readings and pictures that reflect the truth about the world. Data can be taken at face value; they are pre-analytic and rhetorical (Rosenberg 2013). Likewise, the algorithms used to process these data are neutral and non-ideological in their formulation and operation, grounded in scientific objectivity (Kitchin and Dodge 2011). Such a framing of data and algorithms enable smart city projects themselves to present an image of being politically benign and commonsensical; that big data urbanism is inherently a good thing, seeking to make a city safer, more secure, efficient, productive, sustainable and so on by employing rigorous, technical practices that capture, process and analyze vast quantities of transparent, neutral, objective data. Data, however, are more complicated than that. Data do not exist independently of the ideas, techniques, technologies, people and contexts that conceive, produce, process, manage, analyze and store them (Bowker and Star 1999; Lauriault 2012; Ribes and Jackson 2013). As Gitelman and Jackson (2013: 2, following Bowker) put it, "raw data is an oxymoron"; "data are always already 'cooked' and never entirely 'raw'." As such, no data 
are pre-analytic, or are objective, value-free, and benign. What data are generated is the product of choices and constraints, shaped by a system of thought, technical know-how, public and political opinion, ethical considerations, the regulatory environment, and funding and resourcing. Data then are situated, contingent, relational, and framed and used contextually to try and achieve certain aims and goals.

It is no different with big data used to underpin smart urbanism. Whilst big data may seek to be allencompassing, exhaustive and politically benign, as with all data they are a selective sample and are framed within a thought system. What data are captured is shaped by: the field of view/sampling frame (where data capture devices are deployed, what their settings/parameters are, who uses a space or media); the technology and platform used (different surveys, sensors, lens, textual prompts, layout, etc. all produce variances and biases in what data are generated); the context in which data are generated (unfolding events mean data are always situated and contextualised with respect to circumstance); the data ontology employed (how the data are calibrated and classified); and the regulatory environment with respect to privacy, data protection and security (Kitchin 2013). Big data generally captures what is easy to ensnare-data that are openly expressed (what is typed, swiped, scanned, sensed; people's actions and behaviours; the movement of things) - as well as data that are the 'exhaust', a by-product, of the primary task/output. It takes these data at face-value, despite the fact that they may not have been designed to answer specific questions and the data produced might be messy, dirty, full of occlusions and biases. It is less well suited to contextualising such data or revealing the complex contingent and relational inner lifeworlds of people and places. Moreover, the data are generated within systems designed to enact a particular political and policy vision. The result are data that are inflected by social privilege and social values, especially within domains that function as disciplinary systems (such as law enforcement) (Johnson 2013). There is no doubt that big data initiatives do produce data that are useful for understanding and managing cities, but the politics and limitations of such data and the methods used to produce and analyze them need to be teased apart and examined as to the values and agendas underpinning them and whose interests they serve.
Technocratic governance and city development

The drive towards managing and regulating the city via information and analytic systems promotes a technocratic mode of urban governance which presumes that all aspects of a city can be measured and monitored and treated as technical problems which can be addressed through technical solutions; displaying what Mattern (2013) terms 'instrumental rationality' and Morozov (2013) calls 'solutionism', wherein complex social situations can be disassembled into neatly defined problems that can be solved or optimized through computation. Here, there is a reification of big data; they can provide the answer to all problems (Mattern 2013). By capturing a phenomena as real-time data it seemingly becomes possible to model, understand, manage and fix a situation as it unfolds. As Hill (2013) puts it: "[smart city thinking] betrays a technocratic view that the city is something we might understand in detail, if only we had enough data-like an engine or a nuclear power station-and thus master it through the brute force science and engineering." Indeed, Mattern (2013) suggests that big data urbanism suffers from "datafication, the presumption that all meaningful flows and activity can be sensed and measured." Within such thinking there is "an often-explicit assumption that the universe is formed with knowable and definable parameters [that] assures us that if we were only able to measure them all, we would be able to predict and respond with perfection accordingly" (Haque 2012). Employing an evidence-based, algorithmic processed approach to city governance thus seemingly ensures rational, logical, and impartial decisions. Moreover, it provides city managers with a defence against decisions that raise ethical and accountability concerns by enabling them to say, 'It's not me, it's the data!' (Haque 2012).

However, technocratic forms of governance are highly narrow in scope and reductionist and functionalist in approach, based on a limited set of particular kinds of data and failing to take account of the wider effects of culture, politics, policy, governance and capital that shape city life and how it unfolds. Technological solutions on their own are not going to solve the deep rooted structural problems in cities as they do not address their root causes. Rather they only enable the more efficient management of the manifestations of those problems. As such, whilst smart 
city technologies, such as real time analytics are promoted as the panacea for tackling urban governance issues, they largely paper over the cracks rather than fixing them, unless coupled with a range of other policies. Further, control and command systems centralise power and decision making into a select set of offices, at the same time that they make elements of the data publicly available. There is clearly a delicate balance to maintained as new forms of technologically rooted monitoring and management are rolled out. On the one hand, such technologies enable aspects of the city to managed more efficiently and effectively on a dynamic basis rooted in a strong evidence-base. On the other, these data and technologies need to be complemented with a range of other instruments, policies and practices that are sensitive to the diverse ways in which cities are structured and function.

The corporatisation of city governance and a technological lock-in

Alongside the critique that smart city governance is too technocratic in nature is a concern that it is being captured and overtly shaped by corporate interests for their own gain (Greenfield 2013; Townsend 2013). The smart city agenda and associated technologies are being heavily promoted by a number of the world's largest software services and hardware companies who view city governance as a large, long-term potential market for their products. Either through being major partners in building cities from the ground up (e.g., Songdo or Masdar City), or partnering with established cities to retrofit their infrastructure with digital technology and data solutions, these companies have been seeking to make their wares a core, indispensible part of how various aspects of city life are monitored and regulated. As such, as Schaffers et al. (2011: 437) note, "smart city solutions are currently more vendor push than city government pull based", with companies working to build working relationships, put in place favourable market conditions, divert funding streams and create public-private partnerships.

The concern around such a move is three-fold. First, that it actively promotes a neoliberal political economy and the marketisation of public services wherein city functions are administered for private profit (Hollands 2008). Second, that it creates a technological lock-in that beholden cities to particular technological platforms and vendors over a long period of time creating monopoly positions (Hill 2013). The danger here is the creation of a corporate path dependency that cannot easily be undone or diverted (Bates 2012). As Hill (2013) details, the strategy adopted by IT corporations mirrors that of US car manufacturers in the midtwentieth century in creating a form of technology-led urbanism centred on car transportation. Here, public transport networks were closed down to be replaced by a vast road building programme that then shaped patterns of urban development in the following decades. Haque (2012) thus wonders "what the smart city equivalents might be of Robert Moses' tangled, congested and polluted freeways or the failures of the Pruitt Igoe housing complex." Third, that it leads to 'one size fits all smart city in a box' solutions that take little account of the uniqueness of places, peoples and cultures and straightjackets city administrations into a narrowly visioned technocratic mode of governance (Townsend et al. nd). Indeed, IBM is now selling a product called 'IBM Intelligent Operations Center', which combines a number of the systems that were designed for Rio into a single product that can be applied to any city (Singer 2012). Given these concerns, Hill (2013) thus warns that "[1]iterally hardwiring urban services to a particular device, a particular operating system, is a recipe for disaster, not efficiency... Put simply, city fabric changes slowly yet technology changes rapidly... There is a worrying lack of thought about adaptation in this desire to install the consumer tech layer as if it were core building services." That's not say that such a corporate lockin is inevitable, but it is clear that is the desire of a number of very large corporate players.

\section{Buggy, brittle and hackable cities}

The embedding and use of ubiquitous and pervasive computing in city environments is creating city services and spaces that are dependent on software to function. Dodge and Kitchin (2004) term these environments code/spaces, wherein software and the spatiality of everyday life become mutually constituted, so that if the software fails a space is not produced as intended as the old analogue system and associated tacit knowledge has been entirely replaced. For example, if the software used to control a subway system crashes, then the trains do not run (as has 
happened in many cities in the past few years; see Townsend 2013); or if a supermarket's checkout tills crash, shoppers cannot make purchases as goods cannot be scanned or payments made, with the shop effectively becoming a warehouse. As such, whilst potentially solving a diverse set of urban problems, the creation of code/spaces through smart city projects leaves cities vulnerable to other issues. In particular, it has the potential to create buggy, brittle and exposed city services and spaces that are prone to viruses, glitches, crashes, and security hacks that can cause havoc (Kitchin and Dodge 2011; Townsend 2013). As Kitchin and Dodge (2011) detail, software is an unusual product because it is sold in full knowledge that it is inherently partial, provisional, porous and open to failure. Software-enabled technologies, especially those that are networked and distributed, routinely have to be patched and updated to cope with new contingencies. And as systems become ever more complicated, interconnected and dependent on software, the challenge of producing stable, robust and secure devices and infrastructures increases (Townsend 2013).

What are the implications then of creating extensive city systems that are reliant on software to function? Of taking two highly complex, contingent and open systems - cities and information systemsand interweaving them together? Or as Townsend (2013) puts it: "What if the seeds of smart cities' own destruction are already built into their DNA? What if the smart cities of the future are buggy and brittle? What are we getting ourselves into?" He suggests that as more and more systems are layered on top of ICT networks, each in a relatively brittle state, the risks of critical failures and 'normal accidents' (everyday glitches) become compounded. At the same time analogue alternatives are disappearing. Moreover, ever more systems are becoming open to malicious forms of attack. For example, the Israeli government acknowledges that its essential services such as water, electricity, banking, rail and road infrastructure is the target of numerous cyber attacks, with Israel Electric Corp reporting that it receives 6,000 attempted hacks every second (Paganini 2013). And in October 2012, the traffic management system for a major artery in Haifa was hacked causing traffic chaos for hours (Paganini 2013). And beyond critical systems, Mims (2013) reports that smartphones, tablets, and the various devices making up the internet of things are all highly vulnerable to direct attacks that force objects to exceed their design parameters or operate in dangerous ways, misdirection through distorting readings leading to user error and damage, and the theft of information. Whilst the nascent deployment of smart city technologies have had some teething issues, contra to the concerns expressed above they have been relatively robust despite their vulnerabilities. Nonetheless, as more systems are deployed, Townsend concludes: "The only questions will be when smart cities fail, and how much damage they cause when they crash."

The panoptic city?

Over the past couple of decades, with the development of various forms of directed, automated and networked digital technologies, there have been increasing concerns over the rising level of surveillance in societies, explicitly acknowledging the politics of data. It is now possible to track and trace individuals and their actions, interactions and transactions in minute detail across a number of domains (work, travel, consumption, etc.). This level of monitoring has been driven by a growing 'culture of control' that desires 'security, orderliness, risk management and the taming of chance' (Garland 2001, cited in Lyon 2007: 12). However, despite systems becoming more widespread, fine-grained and sophisticated, they have largely operated as independent systems and the notion of a panopticon (an all-seeing vantage point) has remained open to vertical (within an activity) and horizontal (across activities) fragmentation due to agencies communicating imperfectly or being unable or unwilling to exchange or compare information (Hannah 1997). Governance has thus consisted of a set of oligopticons-partial vantage points from fixed positions with limited view sheds (Amin and Thrift 2002).

Big data and data control centres, such as the Centro De Operacoes Prefeitura Do Rio, that integrate and bind data streams together, work to move the various oligopticon systems into a single, panoptic vantage point and raise the spectre of a Big Brother society based on a combination of surveillance (gazing at the world) and dataveillance (trawling through and interconnecting datasets), and a world in which all aspects of a citizen's life are captured and potentially never forgotten (Dodge and Kitchin 2007b). There is an 
inherent tension then in the creation of systems that seek to enable more effective modes of governance which also threaten to stifle rights to privacy, confidentiality, and freedom of expression. As more and more aspects of urban life are captured as data in dynamic ways at finer resolutions, this tension is set to grow and it will be important to balance the benefits of data analytics with individual and societal rights in order to maintain democracy and trust in government, especially when so much of the data will be processed by corporate systems. Without regulated oversight and enforcement concerning abuses of data, then there is likely to significant resistance and push-back against real-time analytics by citizens.

\section{Conclusion}

The notion of smart cities has gained much traction in recent years as a vision for stimulating and supporting innovation and economic growth, and providing sustainable and efficient urban management and development. One significant aspect of the smart cities concept is the production of sophisticated data analytics for understanding, monitoring, regulating and planning the city. As cities have become increasingly embedded with all kinds of digital infrastructure and networks, devices, sensors and actuators, the volume of data produced about them has grown exponentially, providing rich streams of information about cities and their citizens. Such big data are varied, fine-grained, indexical, dynamic and relational enabling real-time analysis of different systems and to interconnect data across systems to provide detailed views of the relationships between data. For citizens such data and its analysis offers insights into city life, aids everyday living and decision-making, and empowers alternative visions for city development. For governments, big data and integrated analysis and control centres offer more efficient and effective city management and regulation. For corporations, big data analytics offers new, long term business opportunities as key players in city governance.

Over the next decade, the real-time city is likely to become a reality in many cities as urban administrations seek to capitalise on new data streams and new commercial products are bought to market that help governments and citizens make sense of the city. Whilst such big data analytics offers a number of opportunities, they also raise a number of concerns with respect to the politics of such data, technocratic governance, the corporatisation and further neoliberalisation of city management, the possibilities of a technological lock-in, system vulnerabilities, ethical issues with respect to surveillance, dataveillance and control, as well as other concerns relating to data quality, fidelity, security, the validity of analytics that utilise data dredging techniques, and how data are interpreted and acted upon. Given the role that such systems are likely to play in shaping urban governance there is a pressing need to interrogate the nature and production of urban big data, the composition and functioning of urban analytics and control centres, and the implications of technocratic, corporatised and realtime forms of governance. This paper has provided some initial entry points, but wider synoptic overviews and in-depth empirical studies are required to examine existing and potential smart urbanism. As Greenfield (2013) and Townsend (2013) argue, without such critical interrogations the smart cities of the future will likely reflect narrow corporate and state visions, rather than the desires of wider society.

Acknowledgments An early version of this paper was originally presented at the 'Smart Urbanism: Utopian Vision or False Dawn' workshop at the University of Durham, 20-21 June 2013. Many thanks to the organisers and attendees for constructive feedback.

\section{References}

Allwinkle, S., \& Cruickshank, P. (2011). Creating smart-er cities: An overview. Journal of Urban Technology, 18(2), $1-16$.

Amin, A., \& Thrift, N. (2002). Cities: Reimagining the Urban. London: Polity.

Bates, J. (2012). "This is what modern deregulation looks like": Co-optation and contestation in the shaping of the UK's Open Government Data Initiative. The Journal of Community Informatics, 8(2). http://www.ci-journal.net/index. php/ciej/article/view/845/916. Accessed 6 Feb 2013.

Batty, M., Axhausen, K. W., Giannotti, F., Pozdnoukhov, A., Bazzani, A., Wachowicz, M., et al. (2012). Smart cities of the future. European Physical Journal Special Topics, 214(1), 481-518.

Bowker, G., \& Star, L. (1999). Sorting things out: Classification and Its consequences. Cambridge: MIT Press.

Boyd, D., \& Crawford, K. (2012). Critical questions for big data. Information, Communication and Society, 15(5), 662-679.

Caragliu, A., Del Bo, C., Nijkamp, P. ( 2009). Smart Cities in Europe. Series Research Memoranda 0048. VU University 
Amsterdam, Faculty of Economics, Business Administration and Econometrics.

Dodge, M., \& Kitchin, R. (2004). Flying through code/space: The real virtuality of air travel. Environment and Planning A, 36(2), 195-211.

Dodge, M., \& Kitchin, R. (2005). Codes of life: Identification codes and the machine-readable world. Environment and Planning D: Society and Space, 23(6), 851-881.

Dodge, M., \& Kitchin, R. (2007a). The automatic management of drivers and driving spaces. Geoforum, 38(2), 264-275.

Dodge, M., \& Kitchin, R. (2007b). Outlines of a world coming in existence': Pervasive computing and the ethics of forgetting. Environment and Planning B, 34(3), 431-445.

Dutton, W. H., Blumler, J. G., \& Kraemer, K. L. (1987). Wired cities: Shaping future communication. New York: Macmillan.

Farber, D. (2013). Counting the internet of things in real time. CINet, July 30th. http://news.cnet.com/8301-11386_357596162-76/counting-the-internet-of-things-in-real-time/. Accessed 18 Sep 2013.

Ferro, E. \& Osella, M. (2013). Eight business model archetypes for PSI re-use. Open Data on the Web workshop. http:// www.w3.org/2013/04/odw/odw13_submission_27.pdf. Accessed 10 May 2013.

Feuer, A. (2013). The Mayor's Geek Squad. New York Times, March 23rd. http://www.nytimes.com/2013/03/24/nyregion/ mayor-bloombergs-geek-squad.html. Accessed 9 May 2013.

Florida, R. (2004). The rise of the creative class. New York: Basic Books.

Gitelman, L., \& Jackson, V. (2013). Introduction. In L. Gitelman (Ed.), "Raw data" is an oxymoron (pp. 1-14). Cambridge: MIT Press.

Graham, S., \& Marvin, S. (1999). Planning cybercities: Integrating telecommunications into urban planning. Town Planning Review, 70(1), 89-114.

Greenfield, A. (2006). Everyware: The dawning age of ubiquitous computing. Boston: New Riders.

Greenfield, A. (2013). Against the Smart City (The City is Here for You to Use). New York: Do Projects.

Hancke, G. P., de Carvalho e Silva, B., \& Hancke, G. P, Jr. (2013). The role of advanced sensing in smart cities. Sensors, 13(1), 393-425.

Hannah, M. (1997). Imperfect panopticism: Envisioning the construction of normal lives. In G. Benko \& U. Strohmayer (Eds.), Space and social theory (pp. 344-360). Oxford: Blackwell.

Haque, U. (2012). What Is a City that It Would Be 'Smart'? Volume \#34: City in a Box. http://volumeproject.org/blog/ 2012/12/21/volume-34-city-in-a-box/.

Hill, D. (2013). On the smart city: Or, a 'manifesto' for smart citizens instead. City of Sound, 1st Feb 2013. http://www. cityofsound.com/blog/2013/02/on-the-smart-city-a-callfor-smart-citizens-instead.html. Accessed 5 Feb 2013.

Hollands, R. G. (2008). Will the real smart city please stand up? City, 12(3), 303-320.

Ishida, T., \& Isbister, K. (2000). Digital cities: Technologies, experiences, and future perspectives. LNCS: Springer. 1765.

Johnson, J.A. (2013). From open data to information justice. Paper presented at the Annual Conference of the Midwest Political Science Association, April 13, 2013, Chicago,
Illinois. http://papers.ssrn.com/abstract $=2241092$. Accessed 16 Aug 2013.

Kitchin, R. (2013). Big data and human geography: Opportunities, challenges and risks. Dialogues in Human Geography.

Kitchin, R., \& Dodge, M. (2011). Code/space: Software and everyday life. Cambridge, MA: MIT Press.

Kloeckl, K., Senn, O., \& Ratti, C. (2012). Enabling the real-time city: LIVE Singapore! Journal of Urban Technology, 19(2), 89-112.

Komninos, N. (2002). Intelligent cities: Innovation. Routledge: Knowledge Systems and Digital Spaces.

Kourtit, K., Nijkamp, P., \& Arribas-Bel, D. (2012). Smart cities perspective-A comparative European study by means of self-organizing maps. Innovation, 25(2), 229-246.

Laney, D. (2001). 3D Data management: Controlling data volume, velocity and variety. Meta Group. http://blogs. gartner.com/doug-laney/files/2012/01/ad949-3D-DataManagement-Controlling-Data-Volume-Velocity-and-Var iety.pdf. Accessed 16 Jan 2013.

Lauriault, T.P. (2012). Data, Infrastructures and Geographical Imaginations: Mapping Data Access Discourses in Canada. $\mathrm{PhD}$ Thesis, Carleton University, Ottawa.

Lyon, D. (2007). Surveillance studies: An overview. Cambridge: Polity.

Manyika, J., Chiu, M., Brown, B., Bughin, J., Dobbs, R., Roxburgh, C., et al. (2011). Big data: The next frontier for innovation, competition, and productivity. McKinsey Global Institute.

Marz, N., \& Warren, J. (2012). Big data: Principles and best practices of scalable realtime data systems. Manning: MEAP edition.

Mattern, S. (2013). Methodolatry and the art of measure: The new wave of urban data science. Design Observer: Places. 5th November 2013. http://designobserver.com/places/ feature/0/38174/. Accessed 15 Nov 2013.

Mayer-Schonberger, V., \& Cukier, K. (2013). Big data: A revolution that will change how we live, work and think. London: John Murray.

Miller, H. J. (2010). The data avalanche is here. Shouldn't we be digging? Journal of Regional Science, 50(1), 181-201.

Mims, C. (2013). Coming soon: the cybercrime of things. The Atlantic, August 6th. http://www.theatlantic.com/technology/ archive/2013/08/coming-soon-the-cybercrime-of-things/ 278409/. Accessed 15 Nov 2013.

Morozov, E. (2013). To save everything, click here: Technology, solutionism, and the urge to fix problems that don't exist. New York: Allen Lane.

Paganini, P. (2013). Israeli road control system hacked, causes traffic jam on Haifa highway. The Hacker News, October 28th. http://thehackernews.com/2013/10/israeli-roadcontrol-system-hacked.html. Accessed 13 Nov 2013.

Rial, N. (2013). The power of big data in Europe. New Europe, May 24th. http://www.neurope.eu/article/power-big-dataeurope. Accessed 27 May 2013.

Ribes, D., \& Jackson, S. J. (2013). Data bite man: The work of sustaining long-term study. In L. Gitelman (Ed.), "Raw data" is an oxymoron (pp. 147-166). Cambridge: MIT Press.

Rosenberg, D. (2013). Data before the fact. In L. Gitelman (Ed.), "Raw data" is an oxymoron (pp. 15-40). Cambridge: MIT Press. 
Schaffers, H., Komninos, N., Pallot, M., Trousse, B., Nilsson, M., \& Oliveira, A. (2011). Smart cities and the future internet: Towards cooperation frameworks for open innovation. In J. Domingue, et al. (Eds.), Future Internet Assembly (pp. 431-446). LNCS: Springer.

Shepard, M. (2011). Sentient city: Ubiquitous computing, architecture, and the future of urban space. Cambridge, Mass: MIT Press.

Singer, N. (2012). Mission control, built for cities: I.B.M. Takes 'Smarter Cities' Concept to Rio de Janeiro. New York Times, 3 March 2012. http://www.nytimes.com/2012/03/ 04/business/ibm-takes-smarter-cities-concept-to-rio-dejaneiro.html. Accessed 9 May 2013.

Smolan, R. \& Erwitt, J. (2012). The Human Face of Big Data. New York: Sterling.
Sui, D., Elwood, S., \& Goodhild, M. (Eds.). (2012). Crowdsourced geographic knowledge: Volunteered geographic information in theory and practice. Dordrecht: Springer.

Townsend, A. (2013). Smart cities: Big data, civic hackers, and the quest for a new utopia. New York: W.W. Norton \& Co.

Townsend, A., Maguire, R., Liebhold, M. \& Crawford, M. (no date) A planet of civic laboratories: The future of cities, information and inclusion. Institute for the Future, Palo Alto.

Zikopoulos, P. C., Eaton, C., deRoos, D., Deutsch, T., \& Lapis, G. (2012). Understanding big data. New York: McGraw Hill. 